\title{
PENGGUNAAN MEDIA BOOKLET BERBASIS HOTS (HIGHER ORDER TINKING SKILL) GURU BAHASA INDONESIA DALAM PEMBELAJARAN CERITA FABEL DI KELAS VII MTS NEGERI 2 BULELENG
}

\author{
Riska Arisma ${ }^{1}$, Ida Ayu Md. Darmayanti ${ }^{2}$, Ida Bagus, Sutresna ${ }^{3}$ \\ Jurusan Pendidikan Bahasa dan Sastra Indonesia, Fakultas Bahasa dan Seni \\ Universitas Pendidikan Ganesha \\ Singaraja, Indonesia \\ e-mail: \{arismariska20@yahoo.co.id, dayudarmayanti1984@yahoo.com, \\ sutresna1956@gmail.com\}@undiksha.ac.id
}

\begin{abstract}
ABSTRAK
Penelitian ini bertujuan mendiskripsikan (1) penggunaan media booklet berbasis HOTS (Higher Order Thinking Skill) dalam pembelajaran cerita fabel di kelas VII dan (2) kendala-kendala yang dihadapi oleh guru saat menggunakan media booklet berbasis HOTS (Higher Order Thinking Skill) dalam pembelajaran cerita fabel di kelas VII MTs Negeri 2 Buleleng. Penelitian ini menggunakan rancangan penelitian deskriptif kualitatif. Subjek penelitian ini adalah guru dan siswa. Objek dalam penelitian ini adalah penggunaan media booklet berbasis HOTS (Higher Order Thinking Skill) dan kendalakendala yang dihadapi oleh guru saat menggunakan media booklet berbasis HOTS (Higher Order Thinking Skill). Metode pengumpulan data yang digunakan adalah metode observasi, dokumentasi, dan wawancara. Data dalam penelitian ini dianalisis secara deskriptif kualitatif. Hasil penelitian ini ialah (1) penggunaan media booklet berbasis HOTS (Higher Order Thinking Skill) dalam pembelajaran cerita fabel telah memenuhi prosedur, yaitu pada awal pembelajaran, guru mampu menggiring siswa; pada inti pembelajaran, siswa mampu mengikuti pembelajaran cerita fabel dengan menggunakan media booklet berbasis HOTS (Higher Order Thinking Skill) dengan maksimal, dan pada akhir pembelajaran siswa mampu menjawab pelatihan HOTS dengan baik. (2) Kendala guru adalah dari segi siswa. Simpulan penelitian ini adalah (1) penggunaan booklet berbasis HOTS (Higher Order Thinking Skill) telah efektif dan sesuai prosedur. (2) Kendala yang ditemukan oleh guru adalah dari segi siswa. Saran penelitian ini ialah, guru bahasa Indonesia agar mempertahankan keefektifan media booklet berbasis HOTS (Higher Order Thinking Skill) dan lebih memotivasi siswa untuk meningkatkan pembelajaran.
\end{abstract}

Kata Kunci: media booklet berbasis HOTS (Higher Order Thinking Skill), pembelajaran, cerita fabel 


\begin{abstract}
This study aimed to describe (1) the use of HOTS-based booklet book (Higher Order Thinking Skill) in learning fable story for seventh grade students and(2) constraints faced by teachers when using HOTS-based booklet (Higher Order Thinking Skill) in learning fable story at seveth grade students in MTs Negeri 2 Buleleng. This study used descriptive qualitative research design. The subjects of this study were teachers and students. The object of this study was the use of HOTS-based booklet book (Higher Order Thinking Skill) and constraints faced by teachers when using HOTS-based booklet (Higher Order Thinking Skill). The data were collected through observation, documentation, and interview. The data in this study were analyzed descriptive qualitatively. The results of this study were (1) the use of HOTS-based booklet book (Higher Order Thinking Skill) in learning fable story has followed the procedure, that is at the beginning the teacher's learning, can lead the students; at the core of learning the students were able to follow the learning of fable story by using HOTS-based booklet (Higher Order Thinking Skill) maximally, and at the end of the learning students were able to answer HOTS training well. (2) the teacher's constraints was in terms of the students. The conclusions of this study were (1) the use of HOTS-based booklets (Higher Order Thinking Skill) has been effective and based on the procedures. (2) the obstacles found by teachers was in terms of the students. The suggestion of this research is, Indonesian teacher should maintain the effectiveness of HOTS-based booklet media (Higher Order Thinking Skill) and motivate the students more to increase their learning.
\end{abstract}

Keywords: HOTS-based booklet medium (Higher Order Thinking Skill), learning, fable story

\title{
PENDAHULUAN
}

Pendidikan merupakan salah satu hak bagi seluruh lapisan masyarakat. Dalam hal ini, hak-hak yang perlu diberikan kepada siswa, baik dari segi kelengkapan diri sendiri, pelayanan, maupun adanya fasilitas yang memadai dari segi sarana dan prasarana dalam melaakukan kegiatan pembelajaran. menurut Gagne dan Brigs (dalam Arsyad 2011: 4), menyatakan bahwa media pembelajaran meliputi alat yang secara fisik digunakan untuk menyampaikan isi materi pengajaran, yang terdiri atas berbagai media, yakni buku, tape recorder, kaset, video camera, video recorder, film, slide (gambar bingkai), foto, gambar, grafik, televise, dan komputer. Penggunaan media tentunya tidak sembarang bisa digunakan, bergantung pada materi yang diajarkan, seperti pembelajaran sastra. Sastra, pada hakikatnya, sebuah karya yang terlahir dari sebuah ide, gagasan, atau imajinasi pengarang. Sutresna (2006: 6) menyatakan bahwa pengarang memiliki daya sorot dan presiasi yang tajam terhadap problema-problema yang ada di masyarakat untuk dijadikan sumber ilham atau ide, yang pada gilirannya dituangkan dalam ungkapan sastra.

Penelitian tentang penggunaan media booklet berbasis HOTS (Higher Order Thinking Skill) pernah dilakukan oleh peneliti lain yang bernama Sinta Ayu Ambarwati pada tahun 2015, ia melakukan penelitian berjudul "Keefektifan Pendekatan Saintifik Berbantuan Booklet Higher Order Thinking Skill terhadap Hasil Belajar Siswa Kelas 
X". Hasil penelitian dan pembahasannya adalah meningkatkan hasil belajar siswa dalam pengunaan pendekatan saintifik berbantuan booklet higher Order thinking skill. Penelitian tersebut hanya melihat aspek efektifitas pendekatan saintifik berbantuan booklet higher order thinking skill dalam pembelajaran Biologi. Semestinya penelitian tersebut tidak hanya meneliti aspek keefektifan, tetapi juga melihat penggunaan, respons, dan kendala yang dialami oleh guru dalam penggunaan media booklet higher Order thinking skill.

Pisau bedah yang digunakan dalam penelitian ini adalah teori cerita fabel yang disampaikan oleh Nurgiyantoro (2005: 190), tokoh binatang tersebut dapat berpikir dan berinteraksi lengkap dengan permasalahan hidup layaknya manusia. Teori lain yang digunakan, yaitu tentang media pembelajaran yang disampaikan oleh Hamalik (dalam Arsyad, 2011: 15), pemakaian media pembelajaran dalam proses pembelajaran mengajar dapat membangkitkan keinginan dan minat yang baru, membangkitkan motivasi dan rangsangan kegiatan belajar, dan bahkan membawa pengaruhpengaruh psikologis terhadap siswa. Selain itu teori HOTS (Higher Order Thinking Skil) yang disampaikan oleh Wardana (dalam Rofiah, 2013: 17), menyatakan bahwa kemampuan berpikir tingkat tinggi atau HOTS adalah proses berpikir yang melibatkan aktivitas mental dalam usaha mengeksplorasi pengalaman yang kompleks, reflektif, dan kreatif yang dilakukan secarasadar untuk mencapai tujuan, yaitu memperoleh pengetahuan, yang meliputi tingkat brpikir anaalisis, sintesis, dan evaluasi.
Selanjutnya teori tentang kendala pembelajaran yang disampaikan oleh Hadisoeparto (2003: 117) bahwa kendala yang disebabkan oleh siswa bisa terjadi apabila dalam proses belajar mengajar siswa tidak berantusias dan merasa kurang termotivasi mengikuti pembelajaran yang dilaksanakan oleh guru.

Metode pembelajaran yang digunakan dalam cerita fabel dibedah menggunakan teori-teori yang relevan dengan data yang diperoleh peneliti. Metode pembelajaran merupakan aspek yang penting dalam kegiatan belajar, karena media pembelajaran dapat melatih keterampilan serta kemampuan berpikir tingkat tinggi siswa dan akan berpengaruh terhadap motivasi dan hasil belajar siswa. Salah satu media pembelajaran yang dapat melatih kemampuan berpikir tingkat tinggi siswa adalah media booklet berbasis HOTS (Higher Order Thinking Skill). Media booklet berbasis HOTS (Higher Order Thinking Skill) telah digunakan guru dalam pembelajaran cerita fabel oleh guru Bahasa Indonesia kelas VII MTs Negeri 2 Buleleng yang bernama Indriana Safitri, S.Pd. bagi guru media booklet berbasis HOTS (Higher Order Thinking Skill) tidak sekadar media pembelajaran tetapi juga merupakan media untuk mengasah kemampuan berpikir tingkat tinggi siswa.

Dengan menggunakan media booklet berbasis HOTS (Higher Order Thinking Skill), siswa tidak hanya termotivasi untuk belajar, namun siswa juga mampu mengasah kemampuan berpikir tingkat tinggi. Dengan demikian, tidak proses pembelajaran akan berjalan sesuai dengan tujuan pembelajaran. dengan demikian, penelitian ini bertujuan 
mendeskripsikan dua hal, yaitu (1) penggunaan media booklet berbasis HOTS (Higher Order Thinking Skill) guru bahasa Indonesia dalam pembelajaran cerita fabel di kelas VII MTs Negeri 2 Buleleng. (2) kendalakendala yang di hadapi oleh guru dalam menggunakan media booklet berbasis HOTS (Higher Order Thinking Skill) dalam pembelajaran cerita fabel di kelas VII MTs Negeri 2 Buleleng. Penelitian ini dapat memberikan manfaat yang bersifat teoretis, hasil penelitian ini diharapkan mampu memberikan sumbangan konseptual yang edukatif pada pendidikan bahasa dan sastra Indonesia, khususnya dalam penggunaan media booklet berbasis HOTS (Higher Order Thinking Skill) guru bahasa Indonesia dalam pembelajaran cerita fabel. Selain itu, peneliti juga dapat memeperkaya khasanah keilmuan, khususnya pengggunaan media booklet berbasis HOTS (Higher Order Thinking Skill) guru bahasa Indonesia dalam pembelajaran cerita fabel. Secara praktis, penelitian ini bermanfaat bagi guru atau pengajar Bahasa dan Sastra Indonesia, termasuk bagi peneliti sendiri sebagai calon guru Bahasa dan Sastra Indonesia hasil penelitian ini diharapkan dapat memperkaya bahan ajar ataupun memperkaya wawasan pengajar dalam pembelajaran cerita fabel. Bagi siswa, penelitian ini dapat digunakan sebagai salah satu acuan dalam pembelajaran cerita fabel. Bagi peneliti lain, pedoman, serta bahan perbandingan atau referensi dalam melakukan penelitian sejenis untuk menambah wawasan peneliti yang dilakukan.

\section{METODE PENELITIAN}

Rancangan penelitian yang digunakan dalam penelitian ini adalah rancangan deskriptif kualitatif. Penelitian ini diharapkan mampu mendeskripsikan penggunaan media booklet berbasis HOTS (Higher Order Thinking Skill) guru bahasa Indonesia dalam pembelajaran cerita fabel di kelas VII MTs Negeri 2 Buleleng.

Subjek penelitian ini adalah guru bahasa Indonesia kelas VII, yaitu Indriana Safitri, S.Pd. dan siswa kelas VII. Sedangkan objek penelitian ini ada dua, yaitu penggunaan media booklet berbasis HOTS (Higher Order Thinking Skill) dalam pembelajaran cerita fabel dan kendala-kendala yang dialami oleh guru dalam menggunakan media booklet berbasis HOTS (Higher Order Thinking Skill) dalam pembelajaran cerita fabel.

Tujuan utama penelitian ini adalah mendapatkan data sesuai dengan masalah penelitian. Metode pengumpulan data yang benar akan menghasilkan data yang memiliki kridibelitas tinggi Suryana (2010: 16) menyatakan bahwa metode penelitian adalah prosedur atau langkah-langkah yang ditempuh dalam penelitian untuk mendapatkan pengetahuan atau ilmu. Oleh karena itu, tahap pengumpulan data tidak boleh salah dan harus dilakukan dengan cermat sesuai prosedur serta ciri-ciri penelitian. Dalam penelitian ini, peneliti menggunakan metode observasi tanpa partisipasi, instrumen yang digunakan adalah lembar observasi dan alat perekam. Peneliti juga menggunakan metode dokumentasi, instrumen yang digunakan adalah dokumen berupa media media booklet berbasis HOTS (Higher Order Thinking Skill). Dan peneliti juga menggunakan metode wawancara, instrumen yang digunakan adalah pedoman wawancara terstruktur 


\begin{abstract}
Selanjutnya, data dalam penelitian ini dianalisis secara deskriptif kualitatif dengan menggunakan prosedur model analisis Miles dan Faisal (dalam Sujarweni, 2014: 34), terdiri atas reduksi data, penyajian data, serta penyimpulan dan verifikasi. Hasil akhir nanti diperoleh informasi mengenai penggunaan media media booklet berbasis HOTS (Higher Order Thinking Skill) dalam pembelajaran cerita fabel guru bahasa Indonesia di kelas VII MTs Negeri 2 Buleleng.
\end{abstract}

\section{HASIL DAN PEMBAHASAN}

Hasil penelitian ini meliputi (1) penggunaan media media booklet berbasis HOTS (Higher Order Thinking Skill) dalam pembelajaran cerita fabel dan (2) kendala-kendal yang dihadapi oleh guru dalam menggunakan media booklet berbasis HOTS (Higher Order Thinking Skill) dalam pembelajaran cerita fabel. Pertama, data menegenai penggunaan media booklet berbasis HOTS (Higher Order Thinking Skill) guru bahasa Indonesia dalam pembelajaran cerita fabel di kelas VII MTs Negeri 2 Buleleng diperoleh menggunakan metode observasi. Kedua, data mengenai kendala-kendala yang yang dihadapi oleh guru dalam menggunakan media booklet berbasis HOTS (Higher Order Thinking Skill) guru bahasa Indonesia dalam pembelajaran cerita fabel di kelas VII MTs Negeri 2 Buleleng diperoleh menggunakan metode wawancara.

Hasil penelitian yang diperoleh akan dibahas satu persatu sebagai berikut. Berbicara tentang cerita fabel tentu tidak asing lagi ditelinga masyarakat, terutama dikalangan pelajar. Cerita fabel sangat berkaitan erat dengan karakter yang bernilai positif bagi pembacanya, melalui pesan-pesan moral yang terungkap dalam cerita, sikap, dan tingkah laku tokoh-tokoh itulah,pembaca diharapkan dapatmengambil hikmah untuk diterapkan (Nurgiyantoro, 1995: 321). Berdasarkan pendapat tersebut, cerita fabel merupakan bagian dari menanmkan pendidikan moral yang dekat dengan kehidupan manusia, terutama di lingkungan pendidikan, seperti halnya di kelas VII MTs Negeri 2 Buleleng. Penggunaan media media booklet berbasis HOTS (Higher Order Thinking Skill) guru bahasa Indonesia dalam pembelajaran cerita di kelas tersebut telah berlangsung efektif dan kondusif, serta memenuhi prosedur. Pada awal pembelajaran guru telah mampu menggiring siswa mengikuti pembelajaran cerita fabel dengan baik. Sebelum memasuki kegiatan inti pembelajaran, guru terlebih dahulu menggali pemahaman siswa tentang materi yang telah dibahas. Hal tersebut terbukti ketika guru bertanya "Sebelumnya, apa yang kalian ketahui tentang fabel?" kepada seluruh siswa. Mendengar pertanyaan tersebut seluruh siswa menjawab dengan serentak mengetahui cerita fabel. Selanjutnya, guru bertanya lagi "Apakah yang dimaksud dengan fabel?" jawaban yang diungkapkan oleh siswa sangatlah beragam, yakni cerita tentang hewan, cerita fiksi, dan cerita hewan yang menyerupai manusia. Setelah guru melakukan apersepsi, guru menyampaikan tujuan pembelajaran secara tertulis. Berdasarkan kegiatan awal tersebut, guru telah mampu menggiring siswa agar mengikuti pembelajaran cerita fabel dengan baik.

Pada kegiatan inti pembelajaran, siswa telah mampu mengiikuti pembelajaran cerita fabel 
dengan menggunakan media booklet berbasis HOTS (Higher Order Thinking Skill) maksimal, berdiskusi dengan baik dan saling tanya jawab. Dalam kegiatan inti, pertama diawali dengan mengamati materi yang telah dipaparkan melalui media booklet berbasis HOTS (Higher Order Thinking Skill) yang telah diberikan oleh guru, kemudian kegiatan kedua, yakni menanya berlangsung terjadilah interaksi antara siswa dan guru salah satu siswa dari kelas VII C bernama Andina Aprilia bertanya "Bu bagaimana cara membedakan cerita fabel adaptasi dan alami?". Guru sangat mengapresiasi pertanyaan tersebut kemudian menjalaskan bahwa pada cerita fabel adaptasi dan alami terletak pada sifat asli tokoh dalam novel dan latar tempat kejadian. Kemudian, kegiatan menanya di kelas VII D bernama Maulidya Sari bertanya terkait komplikasi dalam cerita fabel "Bu, apa yang dimaksud dengan komplikasi atau klimaks dalam cerita fabel?". Guru pun sangat mengapresiasi pertanyaan siswa tersebut dan menjelaskan bahwa komplikasi/klimaks dalam cerita fabel, yakni sama saja dalam karya sastra yang lainnya, klimaks/komplikasi dalam cerita fabel, yakni puncak permasalahan yang ada dalam cerita fabel itu sendiri. Setelah kegiatan menanya ada kegiatan ketiga, yaitu mengeksplorasi (menalar). Pada kegiatan ini guru menugasi siswa untuk mencermati dua buah cerita fabel yang tersedia di dalam media booklet berbasis HOTS (Higher Order Thinking Skill) yag berjudul Iri Hati Sang Merpati dan Si Cantik dan Si Buruk Rupa. Guru meminta siswa untuk mencermati bacaannya kembali agar siswa mampu memahami cerita fabel tersebut.
Kegiatan keempat, yaitu mengasosiasikan, yakni guru menugasi siswa untuk menjawab pertanyaan-pertanyaan yang telah disediakan oleh guru terkait cerita fabel dengan kualitas pertanyaan HOTS (Higher Order Thinking Skill). Pertanyaan ini terdiri atas unsurunsur instrinsik, struktur,dan perbedaan fabel adaptasi dan alami dari kedua cerita fabel di atas. Dari kedua cerita fabel yang telah dibaca siswa juga diminta untuk menganalisis struktur dalam cerita fabel. Kegiatan kelima,yaitu mengomunikasikan. Pada kegiatan ini,guru menunjuk siswa untuk membacakan jawaban yang sudah dikerjakannya. Siswa diminta untuk menjawab pertanyaan-pertanyaan yang ada pada media booklet berbasis HOTS (Higher Order Thinking Skill). Hal tersebut di lakukan agar siswa lain dapat membandingkan hasil kerjanya dengan hasi yang dibicarakan.salah satu siswa bernama Tri Yulie Lestari dari kelas VII B mencoba menjawab pelatihan soal mengenai menentuan fabel alami dan adaptasi pada cerita fabel yang berjudul Iri Hati Sang Merpati dan Si Cantik dan Si Buruk Rupa yang ada dalam kedua cerita fabel tersebut, yakni dengan menjawab berdasarkan tabel yang tertera. Berikut jawaban yang dibacakan di depan kelas, pada cerita fabel Iri Hati Sang Merpati, adapun pertanyaan yang diajukan terkait perbedaan fabel alami dan adaptasi dengan menentukan tokohtokoh, perwatakan, dan latar yang ada di dalam cerita fabeltersebit yakni: pada fabel adaptasi terdapat tokoh yang memiliki perwatakan tidak sesuai dengan kehidupan aslinya, yakni 1) merpati memiliki watak iri hati dan keras kepala,2) latar berada di dalam sangkar, dan kancil memiliki sifat yang bijaksana 
serta bisa berbicara, 3) tekukur baik hati, namun tekukur bisa bertukar sangkar dengan merpati. Sementara itu, di dalam fabel alami, merpati tidak bisa berbicara dengan kancil dan bertukar sangkar dengan tekukur. Setelah siswa selesai membacakan jawabannya, guru memberikan kesempatan bagi siswa lain untuk mengomentari atau menyanggah jawaban temannya.hal tersebut dilakukan untuk mengetahui ketepatan jawaban pekerjaan temannya. Selain itu, kegiatan mengomentari hasil kerja teman juga dapat melatih kemampuan berkomunikasi antarsiswa. Setelah beberapa siswa memberikan komentar maka guru memberikan penjelasan, yakni dalam membedakan antara fabel alami dan adaptasi diperlukan untuk melihat tiga aspek, yakni perwatakan,latar, dan tokoh.

Pada kegiatan penutup, guru menanyakan kesulitan yang dihadapi oleh siswa dalam memamahami materi yang telah dipelajari. Pertanyaan yang digunakan oleh guru untuk menanyakan kesuliutan siswa dalam memahami materi yang telah di pelajari adalah "Bagaimana anakanak, apakah dalam mempelajari cerita fabel dan menjawab pelatihan kalian mengalami kesulitan?". Setelah guru menanyakan kesulitan siswa, guru mengajak siswa untuk menyimpulkan materi pelajaran yang sudah dipelajari. Selanjutnya, guru mengumpulkan lembar kerja siswa untukndinilai dan menutup pelajaran dengan mengucapkan salam.

Berdasarkan hasil observasi yang dilakukan peneliti mengenai penggunaan media booklet berbasis HOTS (Higher Order Thinking Skill) guru bahasa Indonesia dalam pembelajaran cerita fabel di kelas VII MTs Negeri 2 Buleleng, penggunaan media telah efektif untuk meningkatkan minat belajar siswa khususnya dalam materi pembelajaran cerita fabel, selain itu, dalam penggunaan media pembelajaran hal pertama yang harus diketahui oleh guru adalah permasalahan yang dihadapi oleh peserta didik dalam mengikuti pembelajaran. untuk mengatasi permasalahan peserta didik, guru juga harus mampu memilih media yang cocok digunakan untuk memecahkan permasalahan peserta didik. Maka dari itu guru menggunakan media booklet berbasis HOTS (Higher Order Thinking Skill) tersebut. sesuai dengan hasil penelitian media tersebut siswa lebih tertarik mengikuti pembelajaran. hal tersebut dapa dilihat dari hasil observasi yang menunjukan siswa sangat antusias dalam mengikuti pelajaran dan perhatian siswa memang tertuju pada pembelajaran. hal tersebut sejalan dengan hal itu, Sudjana, dkk. (2002: 2), menyatakan bahwa tujuan penggunaan media adalah untuk menarik perhatian siswa sehingga dapat menimbulkan motivasi, untuk memperjelas bahan pelajaran agar siswa lebih mudah memahami, metode mengajar akan lebih bervariasi, dan siswa akan lebih banyak melakukan kegiatan belajar

Yang terakhir adalah tentang kendala guru dalam menggunakan media booklet berbasis HOTS (Higher Order Thinking Skill) dalam pembelajaran cerita fabel ada satu, yaitu dari segi siswa berdasarkan hasil wawancara peneliti dengan guru Bahasa Indonesia kelas VII yang bernama Indriana Safitri, S.Pd, guru menyampaikan bahwa dari segi siswa, beberapa siswa mengalami kesulitan dalam memahami penggunaan bahasa yang ada pada media booklet berbasis HOTS 
(Higher Order Thinking Skill) dikarenakan kurangnya kosakata baku yang dimiliki oleh siswa. Berikut kutipan jawaban guru.

Ibu Indriana: "Ada. Salah satunya yang paling menonjol adalah siswa kesulitan memahami dari segi penggunaan bahasa dikarenakan kurangnya memahami kosakata baku yang dimiliki oleh siswa, tapi hanya beberapa siswa saja yang masih kesulitan memahami kebahasaan dan penyajian pellatihan cerita fabel itu sendiri".

Berdasarkan jawaban yang diberikan oleh guru, sebagaian besar siswa telah mampu mengikuti penggunaan media booklet berbasis HOTS (Higher Order Thinking Skill) dalam pembelajaran cerita fabel dengan baik. Hal tersebut terbukti berdasarkan hasil pembelajaran cerita fabel sebagian besar siswa sudah mampu menjawab pelatihanpelatihan, bahkan, berani maju kedepan di hadapan temantemannya untuk menyampaikan jawabannya dan sudah mencapai nilai di atas KKM. Namun, sebagian kecil siswa kurang mampu mengikuti pembelajaran cerita fabel dengan baik. Pada intinya, kendala yang bersumber dari siswa karena kurangnya antusias siswa ketika mengikuti pembelajaran dan keterbatasan kemampuan siswa. Hal itu senada dengan pandangan Hadiesoeparto (2003: 117) bahwa kendala yang disebabkan oleh siswa bisa terjadi apabila dalam proses belajar mengajar siswa tidak bersntusisas dan merasa kurang termoivasi mengikuti pembelajaran yang dilaksanakan oleh guru. Siswa yang kurang mampu mengikuti kegiatan belajar dengan maksimal, akan menghambat tujuan pembelajaran. dengan demikian, pada pembelajaran cerita fabel, guru harus lebih intens membimbing siswa memiliki motivasi belajar yang tinggi.

\section{IMPLIKASI PENELITIAN}

Penelitian ini berimplikasi membuka peluang dalam penelitian penggunaan media, khususnya penelitian penggunaan media dalam pembelajaran karya sastra khususnya pembelajaran cerita fabel, yakni berupa media booklet berbasis HOTS (Higher Order Thinking Skill). Selain itu, melalui penelitian ini akan terbuka jalan bagi upaya-upaya menciptakan media yang kreatif serta inovatif guna menarik minat serta antusias siswa dalam mengikuti proses pembelajaran dan mampu mengasah kemampuan berpikir tingkat tinggi siswa dengan baik. Oleh karena itu, penelitian ini menghubungkan penggunaan media dan proses pembelajaran, maka ini dapat berimplikasi pula dalam membuka wawasan guru untuk lebih kreatif dan inovatif dalam menggunakan/memilih media atau bahan ajar khususnya dalam pembelajaran cerita fabel. Penelitian ini juga memberikan lebih banyak ruang bagi siswa dalam mengapresiasi sebuah karya sastra khususnya dalam pembelajaran cerita fabel.

\section{SIMPULAN DAN SARAN}

Ada bebrapa simpulan yang dapat diambil berdasarkan hasil dan pembahasan penelitian yaitu, (1) penggunaan media booklet berbasis HOTS (Higher Order Thinking Skill) telah berlangsung efektif dan kondusif, serta memenuhi prosedur. Pada awal pembelajaran guru telah 
mampu menggiring siswa mengikuti pembelajaran cerita fabel dengan baik. Siswa mengikuti pembelajaran debat dengan antusias dan suasana kelas menjadi kondisif. Pada inti pembelajaran siswa telah mampu mengikuti pembelajaran cerita fabel dengan menggunakan media booklet berbasis HOTS (Higher Order Thinking Skill) dengan maksimal. Guru menerapkan pola 5 M (mengamati, menanya, mengeksplorasi, mengasosiasi, dan mengomunikasikan) karena dalamproses pembelajaran di MTs Negeri 2 Buleleng menggunakan kurikulum 2013. Pada kegiatan ini guru mengajak siswa untuk memahami materi mengenai cerita fabel, kemudian melakukan sesi tanya jawab mengenai materi yang dijelaskan, kemudian guru membagikan media booklet berbasis HOTS (Higher Order Thinking Skill) tersebut. Guru menugasi siswa untuk mengerjakan latihan-latihan yang ada dalam media. Siswa diminta membacakan jawaban dihadapan kelas dan siswa yang lain memberikan komentar atau argumentasi. Pada akhir pembelajaran guru menanyakan kesulitan yang dihadapi oleh siswa dalam memahami materi yang telah dipelajari, guru juga mengajak siswa untuk menyimpulkan materi pembelajaran yang sudah dipelajari, dan yang terakhir guru mengumpulkan hasil kerja siswa. Kendala-kandala yang dihadapi oleh guru dalam menggunakan media booklet berbasis HOTS (Higher Order Thinking Skill) pada pembelajaran cerita fabel, yaitu dari segi siswa. Sebagian kecil siswa kurang memahami penggunaan bahasa yang tertera pada media booklet berbasis HOTS (Higher Order Thinking Skill) disebabkan oleh kurangnya kosakata baku yang dimiliki oleh siswa. Penelitian ini berimplikasi membuaka peluang dalam penelitian penggunaan media, khususnya penelitian penggunaan media dalam pembelajaran karya satra khususnya dalam pembelajaran cerita fabel yakni berupa media booklet berbasis HOTS (Higher Orde Thinking Skill). Selain itu, melalui penelitian ini akan terbuka jalan bagi upaya-upaya menciptakan media yang kreatif serta inovatif guna menarik siswa dalam mengikuti proses pembelajaran dan mampu mengasah kemampuan berpikir tingkat tinggi siswa dengan baik. Oleh karena itu, penelitian ini menghubungkan penggunaan media dan proses pembelajaran, maka ini dapat berimplikasi pula dalam membuka wawasan guru untuk lebih kreatif dan inovatif dalam menggunakan/memilih media atau bahan ajar khususnya dalam pembelajaran cerita fabel. Penelitian ini, juga memberikan lebih banyak ruang bagi siswa dalam mengapresiasi sebuah karya sastra khususnya dalam pembelajaran cerita fabel.

Berdasarkan pemaparan mengenai hasil penelitian dan simpulan, ada dua saran yang dapat disampaikan dalam penelitian ini.

Pertama,disarankan kepada guru Bahasa Indonesia tersebut agar mempertahankan keefektifan pembelajaran cerita fabel bahkan harus berupaya meningkatkan keefektifan penggunaan media booklet berbasis HOTS (Higher Order Thinking Skill) dalam pemebeljaran cerita fabel. Disarankan juga kepada guru Bahasa Indonesia yang lain agar mencoba menggunakan media booklet berbasis HOTS (Higher Order Thinking Skill) dalam kegiatan 
mengajar di kelas, karena media booklet berbasis HOTS (Higher Order Thinking Skill) bermanfaat untuk melatih keterampilan berpikir tingkat tinggi siswa. Kedua, Kendala guru dalam menggunakan media booklet berbasis HOTS (Higher Order Thinking Skill) dala pembelajaran cerita fabel di kelas VII MTs Negeri 2 Buleleng, yaitu dari segi siswa. Oleh karena itu, disarankan kepada siswa agar lebih giat belajar dan berlatih di sekolah maupun di luar sekolah. Ketiga, penelitian ini masih terbatas karena hanya meneliti penggunaan media booklet berbasis HOTS (Higher Order Thinking Skill) dalam pembelajaran cerita fabel dan kendala-kendala yang dihadapi oleh guru dari penggunaan media booklet berbasis HOTS (Higher Order Thinking Skill) dalam pembelajaran cerita fabel saja. Untuk menambah khasanah keilmuan, khususnya di bidang bahasa Indonesia. Oleh karena itu, disankan kepada peneliti lain untuk meneliti penggunaan media booklet berbasis HOTS (Higher Order Thinking Skill) dalam materi lainnya, seperti dalam pembelajaran cerita rakyat, cerita fantasi,dan lain-lain.

\section{DAFTAR RUJUKAN}

Ambarwati, Sinta Ayu. 2015. Keefektifan Pendekatan Saintifik Berbantuan Booklet Higher Order Thiking Skill terhadap Hasil Belajar Siswa Kelas X. Skripsi (tidak diterbitkan). Universitas Negeri Semarang.

Arsyad, Azhar. 2011. Media Pembelajaran. Jakarta: PT. Raja Grafindo Persada.
Hadisoeparto, A. 2003. Kesulitan Belajar Mengajar. Jakarta: Bina Aksara.

Nurgiyantoro, Burhan. 1998. Penilaian Pembelajaran Bahasa Berbasis Kompetensi. Yogyakarta: BPE-YOGYAKARTA.

Nurgiyanto, Burhan. 1995. Teori Pengkajian Fiksi. Yogyakarta: Gajah Mada.

Nurgiyantoro, Burhan. 2005. Sastra Anak. Yogyakarta: Gajah Mada University Press.

Rofiah, Emi, dkk. 2013. "Penyusunan Instrumen Tes Kemampuan Berpikir Tingkat Tinggi Fisika pada Siswa SMP". Jurnal Pendidikan Fisika, Vol.1, No. 2, ISSN: 2238-0691.

Sudjana, Nana dan Rivai Ahmad. 2002. Media Pembelajaran. Bandung: Sinar Baru.

Sujarweni, Wiratna. 2014. Metodologi Penelitian. Yogyakarta: PUSTAKABARUPRESS.

Suryana. 2010. Metodologi Penelitian Model Praktis Kuantitatif dan Kualitatif. Buku Ajar Perkuliahan (belum diterbitkan). Bandung, Universitas Pendidikan Indonesia.

Sutresna, Ida Bagus. 2006. Modul Prosa Fiksi. Singaraja: Universitas Pendidikan Ganesha.

Syafudin, Anwar Rizky. 2016. Pengembangan Media Adobe Flash CS5 untuk Pembelajaran Menulis 
Volume 8 Nomor 2, Agustus 2018

P-ISSN : 2614-4743 (cetak) dan e-ISSN : 2614-2007 (online)

Teks Fabel bagi Siswa

Kelas VIII SMP/MTs.

Skripsi (tidak diterbitkan).

Universitas Negeri

Yogyakarta. 


\section{KEMENTERIAN RISET, TEKNOLOGI DAN PENDIDIKAN TINGGI UNIVERSITAS PENDIDIKAN GANESHA FAKULTAS BAHASA DAN SENI} TIM e-JOURNAL PENDIDIKAN BAHASA DAN SASTRA INDONESIA

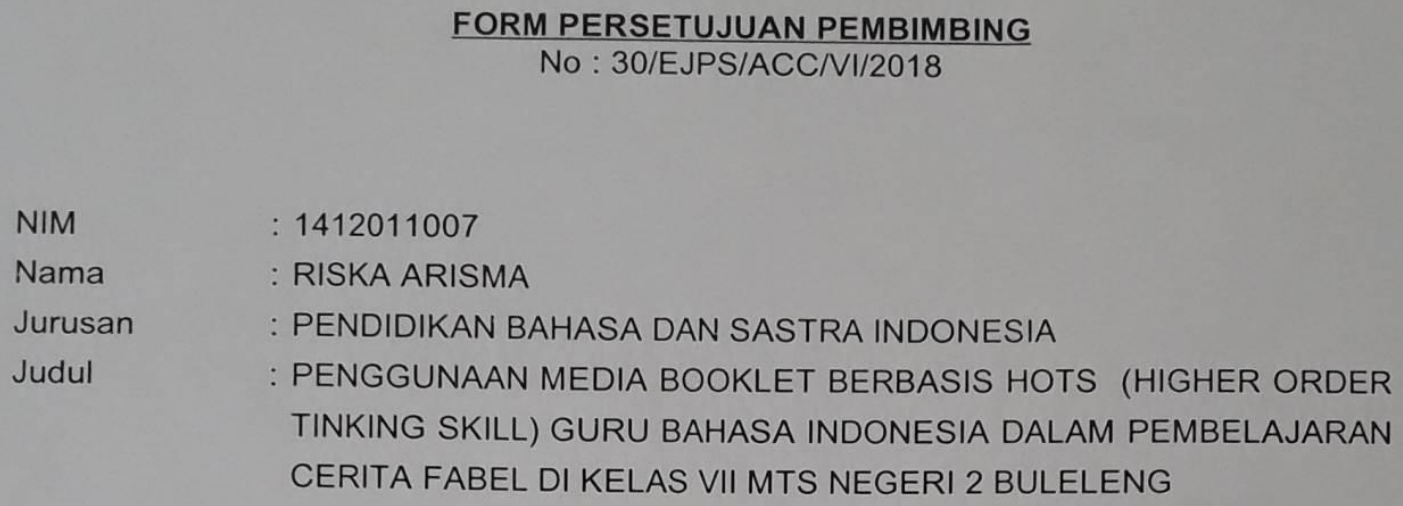

Dengan ini menyatakan bahwa artikel dengan judul di atas sudah diperiksa dan disetujui oleh :

Pembimbing I

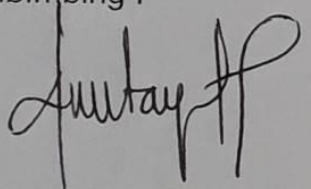

Ida Ayu Made Darmayanti, S.Pd., M.Pd.

NIP. 198402072008122004
Pembimbing II

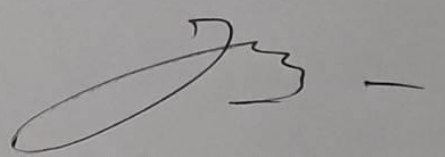

Drs. Ida Bagus Sutresna,M.Si. NIP. 195610131983031003 